\title{
The Use of Patient Reported Outcome Measures (PROMs) 6 Months Post-Stroke and Their Association with the National Institute of Health Stroke Scale (NIHSS) on Admission to Hospital
}

\author{
Jonathan Hewitt ${ }^{1, *(\mathbb{D}}$, Natalie Bains ${ }^{1}$, Katherine Wallis ${ }^{1}$, Stephanie Gething ${ }^{1}$, Anna Pennington ${ }^{1}$ and Ben Carter $^{2}$ \\ 1 Division of Population Medicine, Cardiff University, Cardiff CF10 3AT, UK; bainsnm@cardiff.ac.uk (N.B.); \\ wallisk@cardiff.ac.uk (K.W.); gethings@cardiff.ac.uk (S.G.); anna.pennington@wales.nhs.uk (A.P.) \\ 2 Department of Biostatistics and Health Informatics, Institute of Psychiatry, Psychology \& Neuroscience, \\ King's College London, London WC2R 2LS, UK; ben.carter@kcl.ac.uk \\ * Correspondence: hewittj2@cardiff.ac.uk; Tel.:+44-2920-716982
}

Citation: Hewitt, J.; Bains, N.; Wallis, K.; Gething, S.; Pennington, A.; Carter, B. The Use of Patient Reported Outcome Measures (PROMs) 6 Months Post-Stroke and Their Association with the National Institute of Health Stroke Scale (NIHSS) on Admission to Hospital. Geriatrics 2021, 6, 88. https:// doi.org/10.3390/geriatrics6030088

Academic Editors: Patricia Schofield and David G. Smithard

Received: 24 June 2021

Accepted: 4 September 2021

Published: 7 September 2021

Publisher's Note: MDPI stays neutral with regard to jurisdictional claims in published maps and institutional affiliations.

Copyright: (c) 2021 by the authors. Licensee MDPI, Basel, Switzerland. This article is an open access article distributed under the terms and conditions of the Creative Commons Attribution (CC BY) license (https:// creativecommons.org/licenses/by/ $4.0 /)$.

\begin{abstract}
Patient Reported Outcome Measures (PROMs) assess clinical outcomes from the perspective of the patient. The stroke community recommended fifteen questions for use in stroke survivors, based on the established PROMIS10 with five additional stroke-specific questions. This study aimed to determine its association with the National Institute of Health Stroke Scale (NIHSS) on admission. PROM responses were taken from an existing randomised control trial and, using secondary analysis, the total score was calculated out of 100. The association between PROMs and NIHSS was estimated. Using a multivariable regression, an adjusted mean difference (aMD) in PROM total score for the baseline clinical characteristics was calculated. 343 participants (16.3\%) completed the PROM; mean age 71.7 (30-94) years; 133 women (38.8\%). There was a strong association between increasing NIHSS Scores on admission to hospital and worsening PROM scores at 6 months $(p=0.002)$. There was consistency between the NIHSS and modified Rankin score with the stroke-specific domain and total PROM scores. When adjusted, women had lower (worse) total PROM scores, with aMD $=-3.85$ $(95 \% \mathrm{CI}-6.30--1.41 ; p=0.002)$ and so did haemorrhagic strokes, with a reduction of 3.88 (95\% CI $-0.61-7.37 ; p=0.097)$. This study contributes to the evaluation process of this stroke-specific PROM and emphasises that stroke severity on admission correlates with poorer patient outcomes 6 months following a stroke, especially in women and those suffering haemorrhagic stroke.
\end{abstract}

Keywords: patient reported outcome measures; PROMs; stroke

\section{Introduction}

Patient reported outcome measures (PROMs) are standardised and validated assessments which consider clinical outcomes from the perspective of the patient, rather than the health care provider. They are becoming increasingly common and focus on a patient's personal view of their health following an illness or intervention.

Numerous generic PROMs are available, ranging in length and complexity. For example, the widely used EQ5D, which is a short, simple and validated measure, or the longer SF36, which is based on eight different health domains [1,2]. Many generic PROMs have been used in stroke survivors, but they lack specific relevance to stroke survivors and the clinical conditions they suffer [3].

To help address this problem, Salinas et al. (2016) developed a patient reported outcome measure for use in stroke survivors [4]. This PROMs, developed together by clinicians and stroke survivors, consists of fifteen questions. Ten questions were taken from the PROMIS-10, an established PROM with a mental and physical health domain. An additional five stroke-specific questions were developed by the International Con- 
sortium for Health Outcomes Measurement (ICHOM) [4,5], however, this questionnaire requires validation.

The aims of the study were to determine if there is an association between the NIHSS on admission to hospital and the stroke-specific 15 Patient Reported Outcome Measure (PROM) questions, asked six months following a stroke. Secondary outcomes included validating the two domains of the PROMIS10 questionnaire and one stroke-specific domain, as well as to determine demographic predictors of worsening severity on the PROM.

\section{Materials and Methods}

\subsection{Trial Design}

Patients receive a post-diagnosis 6-month review as part of their routine care. Responses from 15 patient reported outcome measures (PROMs) were collected from stroke survivors in this review, in a Zelen's design non-inferiority randomised controlled trial of four follow up assessment methods; face-to face, telephone, online or by post [6]. The full protocol and results to assess the follow up rates are available [6,7]. Patient demographics, clinical characteristics and health-related data were collected on admission; this included the classification of stroke (ischaemic or haemorrhagic) as defined by the International Classification of Diseases (ICD) [8]. Each participant's stroke severity score, measured using the National Institute of Health Stroke Scale (NIHSS) $[9,10]$ and the Rankin Focussed Assessment Score [11] were collated as per hospital guidelines. The NIHSS is performed by a healthcare professional in the acute period following a stroke. Using 11 elements relating to neurological function, the NIHSS is scored between zero and 42 , with 42 representing the most severe stroke. The NIHSS scores can be grouped according to stroke severity into minor (1-4), moderate (5-15), moderate to severe (16-20) and severe stroke (21-42). During follow up assessment at six months, participants then completed the 15 Patient Reported Outcome Measures (PROMs).

\subsection{Scoring of PROMs}

The fifteen Patient Reported Outcome Measures (PROMs) included ten questions from the PROMIS-10 v1.2 [12,13] and five additional stroke-specific questions. Three additional questions, relating to ambulation, toileting and dressing were implemented from the RiksStroke Questionnaire $[14,15]$ and two questions from the ICHOM Stroke Standard Set were used to assess feeding and communication [4] (Figure A1).

The PROMIS-10 consists of ten equally weighted questions, with a mental and physical health domain, each with a total raw score between 4 and 20. Higher scores indicate better clinical outcomes and participant's raw scores were converted to their equivalent $t$-score as defined by the Global Health Scoring Tool [16].

The additional five specific stroke questions (taken from the ICHOM and Riks-Stroke) consisted of both ordinal and dichotomous data. These were scored to give a total raw score for the stroke-specific domain of between four and ten, again with a higher score indicating a better outcome. These were scaled to give an equivalent $t$-score as for those in the mental and physical health domains of the PROMIS10 questionnaire.

Each question from PROMIS-10, Riks-Stroke and ICHOM was equally weighted, then summed and scaled to give a total maximum score out of 100 .

\subsection{Missing Data}

Mean imputation was used within each PROM domain for participants with a completion rate of over $75 \%$ to predict the missing data. Participants who consented and completed the baseline characteristics but failed to complete the PROM were included in the followed-up population $(n=348)$, but not included in the PROM population used for the main analysis population $(n=343)$. 


\subsection{Statistical Analysis}

An analysis of all participants was undertaken to describe the external validity of the population, comparing the participants that were followed up versus those that were not. A comparison of baseline clinical characteristics was completed. Linear regression of the NIHSS and the PROM was completed. A summary of the PROM domains (mental health, physical health and stroke-specific function) and total was conducted for each of the clinical characteristics.

We analysed the PROM total score in a crude and multivariable regression model, adjusted by participant age group, sex, classification of stroke and recruitment site. Adjusted mean differences (aMD) are presented with associated $95 \%$ confidence intervals calculations (95\% CI), Stata version 15 was used.

\section{Results}

Participants were recruited between July 2017 and January 2018 across 14 centres within England and Wales. In total, 2074 participants were randomised to the trial, 458 participants $(22.5 \%)$ were consented and $343(16.3 \%)$ participants followed up. Those followed up were younger (mean age $=71.8$ years $[\mathrm{SD}=11.0]$ ) and had a lower NIHSS score $($ mean $=5.3[4.8]$ ), whereas non-responders were older (mean age $=73.2$ [13.6]), with a higher NIHSS score (mean = 6.3 [6.2]), demonstrated in Figure A1.

The demographic profiles of the participants who completed the PROM are provided in Table 1. There were 133 (38.8\%) women, with a mean age of 71.7 years (30-94). Patient symptom severity was measured using the NIHSS, modified Rankin and PROMs. Using the NIHSS, 23 (6.9\%) had no symptoms, $164(47.8 \%)$ had mild symptoms, $132(38.5 \%)$ had moderate symptoms and $17(5.0 \%)$ had more severe symptoms. Using the modified Rankin, 92 people $(33.3 \%)$ had no symptoms $(\mathrm{mRS}=0), 80(29.0 \%)$ were scored with no noticeable disability $(\mathrm{mRS}=1)$ and $104(30.3 \%)$ had more severe symptoms. Observation of PROM scores showed $56.8 \%$ of the severe cases were female, compared to just $28.8 \%$ of mild cases. Remaining clinical characteristics appeared to have little difference.

Table 1. Baseline demographics and descriptive analyses of all participants.

\begin{tabular}{|c|c|c|}
\hline Number of Participants & & $\begin{array}{c}\text { Total } \\
343\end{array}$ \\
\hline \multirow{4}{*}{ Grouped Age } & $<60$ & $47(13.7 \%)$ \\
\hline & $60-69$ & $91(26.5 \%)$ \\
\hline & $70-79$ & $121(35.3 \%)$ \\
\hline & $80>$ & $83(24.2 \%)$ \\
\hline \multirow{2}{*}{ Sex } & Female & $133(38.8 \%)$ \\
\hline & Male & $210(61.2 \%)$ \\
\hline \multirow[t]{3}{*}{ Carer Assisted } & Yes & $44(12.8 \%)$ \\
\hline & No Symptoms & $23(6.9 \%)$ \\
\hline & Mild & $164(47.8 \%)$ \\
\hline \multirow{4}{*}{ NIHSS Grouped Frequencies } & Moderate & $132(38.5 \%)$ \\
\hline & Moderate-Severe & $14(4.1 \%)$ \\
\hline & Severe & $3(0.9 \%)$ \\
\hline & Missing & $7(2.0 \%)$ \\
\hline \multirow[t]{4}{*}{ Thrombolysis Status } & Received & $69(20.5 \%)$ \\
\hline & 0 & $92(33.3 \%)$ \\
\hline & 1 & $80(29.0 \%)$ \\
\hline & 2 & $39(14.1 \%)$ \\
\hline \multirow[t]{5}{*}{ Rankin Classification } & 3 & $43(15.6 \%)$ \\
\hline & 4 & $20(7.2 \%)$ \\
\hline & 5 & $2(0.7 \%)$ \\
\hline & Missing & $67(24.3 \%)$ \\
\hline & Ischaemic & $304(88.6 \%)$ \\
\hline \multirow[t]{2}{*}{ Stroke Classification } & Haemorrhagic & $34(9.9 \%)$ \\
\hline & Not Specific & $5(1.5 \%)$ \\
\hline
\end{tabular}


After the total PROM score was adjusted to predict the total NIHSS score, there was a strong association with the slope coefficient estimated as $-0.10(95 \% \mathrm{CI}-0.14--0.05$; $p<0.001)$. Therefore, for an increase of 10 in the total PROM score, there was an estimated reduction in the NIHSS total score of 1 (95\% CI 0.50-1.40).

Each of the three domains of the PROM were found to map to the clinical characteristics. Additionally, consistency was seen between patients with worse NIHSS, higher modified Rankin scores and lower total PROM scores. For example, patients that were independent exhibited a t-score mean of $64.55(\mathrm{SD}=6.10)$ for the stroke-specific domain, compared to 53.56 (10.69) for those who were carer-assisted (Table 2). Similar findings were seen in the total PROM score when observing the difference between asymptomatic patients and those with severe symptoms in the NIHSS (Table 2).

Table 2. Clinical characteristics of the PROM domain score mean (SD).

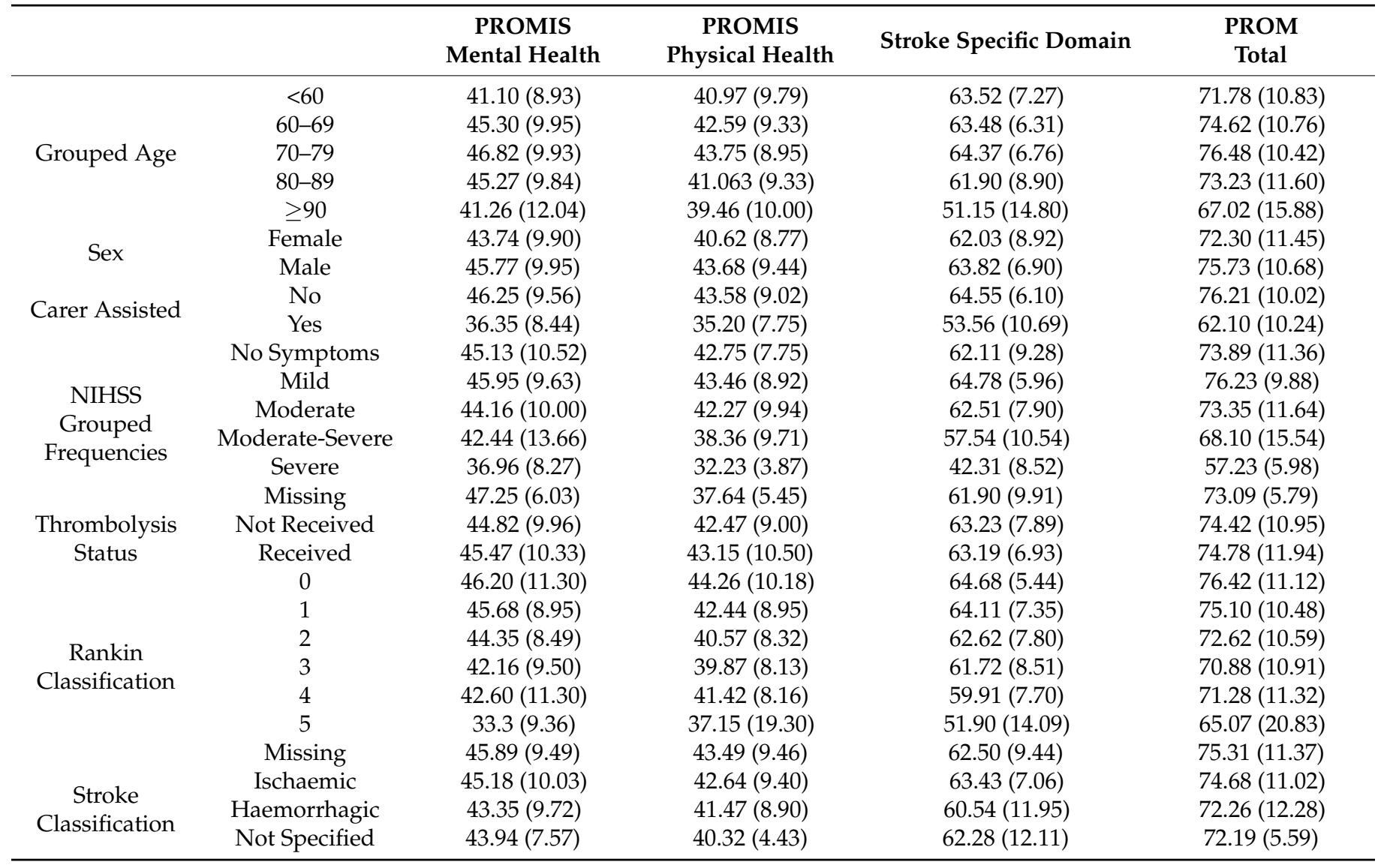

\section{Statistical Analysis}

Women reported a lower PROM when compared to men with a mean difference (MD) of $-3.42(95 \% \mathrm{CI}-5.82--1.53 ; p=0.005$; Table 3$)$, and those completing the PROM aged 70 to 80 reported a higher PROM (MD $=4.70 ; 95 \%$ CI 0.98-8.42; $p=0.01)$ compared to those aged under 60. Adjustments were made for participant's age group, sex, stroke classification and recruitment site in a multivariable linear model. We found a lower PROM with the adjusted MD (aMD) of 3.85 (95\% CI $-6.30-1.41 ; p=0.002$; Table 3) for women. Similar findings were found in the crude analyses of the remaining two mediators, with aMD reduction of 3.88 (95\% CI $-0.61-7.37 ; p=0.097)$ for haemorrhagic stroke classification. For age groups, the aMD for 70-79-year-olds had a higher PROM score compared to patients under $60(\mathrm{aMD}=4.47,95 \%$ CI $0.69-8.25 ; p=0.002)$. 
Table 3. Clinical characteristics associated with the PROM total score.

\begin{tabular}{|c|c|c|c|c|c|}
\hline & & $\begin{array}{c}\text { Crude Mean } \\
\text { Difference }(95 \% \text { CI })\end{array}$ & $p$-Value & $\begin{array}{c}\text { Adjusted Mean } \\
\text { Difference }(95 \% \text { CI) }\end{array}$ & $p$-Value \\
\hline \multirow{4}{*}{ Grouped Age } & $<60$ & Ref & Ref & Ref & Ref \\
\hline & $60-69$ & $2.84(-1.04,6.72)$ & 0.151 & $2.13(-1.82,6.09)$ & 0.290 \\
\hline & $70-79$ & $4.70(0.98,8.42)$ & 0.013 & $4.47(0.69,8.25)$ & 0.020 \\
\hline & $\geq 80$ & $0.85(-3.08,4.79)$ & 0.670 & $0.39(-3.62,4.40)$ & 0.849 \\
\hline \multirow{2}{*}{ Sex } & Male & Ref & Ref & Ref & Ref \\
\hline & Female & $-3.42(-5.82,-1.03)$ & 0.005 & $-3.85(-6.30,-1.41)$ & 0.002 \\
\hline \multirow{3}{*}{$\begin{array}{c}\text { Stroke } \\
\text { Classification }\end{array}$} & Ischaemic & Ref & Ref & Ref & Ref \\
\hline & Haemorrhagic & $-2.42(-6.37,1.53)$ & 0.228 & $-3.38(-7.37,0.61)$ & 0.097 \\
\hline & Other & $-2.49(-12.33,7.35)$ & 0.619 & $-4.05(-14.15,6.06)$ & 0.431 \\
\hline
\end{tabular}

\section{Discussion}

Long-term medical outcomes are being increasingly reported across all medical specialities, including stroke, using PROMs to assess a condition and its symptom burden from a patient's perspective. Within stroke as a subspecialty, several of these outcome measures exist $[17,18]$, however, they were not felt to truly capture the long-term impact of stroke from a patient's perspective. A new set of PROMs was developed in 2016 [4], consisting of 15 questions, which is being established and evaluated within the stroke community [6]. It was developed by consensus, involving a range of stroke specialists, stroke survivors and experts in outcome standard set development. These results constitute the largest use of this stroke-specific PROM to date, and therefore are likely representative of a UK stroke population. This study contributes to the evaluation process of this stroke-specific PROM, whilst confirming that strokes which are severe on admission, as demonstrated by NIHSS, also result in poorer PROMs at six months post-stroke. While these results are to some extent, to be expected, they will highlight to clinicians the likelihood of comorbidity, both physical and mental, which will facilitate earlier interventions and patient-centred discussion.

This study used randomly selected data acquired from a population which is representative of stroke survivors. This population was predominantly in the community following hospital discharge. It demonstrated that PROMs reported six-months following a stroke are correlated with the severity of stroke calculated on admission. Stroke severity is determined by a multitude of factors including the type of stroke and pre-hospital response time, as well as a patient's perception of symptom severity. A rapid response is influenced by speed of first contact with emergency services, location in a rural or urban area and recognition of stroke symptoms (which itself is affected by patient education and those living alone) $[19,20]$.

Interestingly, females with the equal NIHSS as males on admission reported worse symptoms at six months. This is supported by a review of sex differences within stroke which showed women have lower odds of a good outcome and higher prevalence of poststroke depression [21]. Women report worse outcomes following acute illnesses [22-24], these differences are found to be significant even when adjusting for clinical variables such as age and pre-stroke health [21], although there is little understanding as to why these differences occur. Within stroke, women have been shown to experience aphasic disorders, visual field disturbances and dysphagia to a greater extent than men [25]. Overall, this increased morbidity following stroke in women is likely to contribute to worse patient reported outcomes measures [26].

Similar results were seen in patients suffering haemorrhagic strokes, who also had lower PROM scores. This would be in keeping with expectations, as haemorrhagic strokes are associated with poorer clinical outcomes across most existing outcome measures $[27,28]$.

The reasons for a lack of association with increasing age, admission NIHSS score and PROM score is less clear. Typically, all stroke outcomes worsen with increasing age [29]. The statistical correlation was observed in people aged 70-79 years, the largest group 
within this study, which raises the possibility of a lack of power to detect any changes in the other groups. Thus, the findings relating to age should be interpreted with caution.

A large study that compared several commonly-used PROMs concluded they are necessary to provide additional information beyond the traditional clinician-reported measures such as NIHSS or the modified Rankin Scale [30]. In this study, NIHSS had the lowest percentage of improvement or worsening of any of the scores evaluated, suggesting PROMs with psychosocial domains more accurately reflect a patient's recovery [30]. However, collection of this information may be restricted by stroke severity, with severely impaired patients being unable to complete PROMs. Whilst proxies could be used, psychosocial domains may be difficult to accurately assess.

This study does have some limitations, with the data representing a secondary analysis of an RCT. The stroke survivors consenting to the study were shown to have a better admission NIHSS than those who did not consent. This implies that our participants are fitter than the stroke population as a whole, which limits generalisability. Additionally, baseline patient demographics and clinical demographics (regarding stroke) were collected, however, no data was collected on patient comorbidity. Patients with other physical and mental health conditions are likely to score worse on the mental health and physical health domains of the PROM, which we could not account for, potentially skewing our data.

\section{Conclusions}

This study demonstrates that Patient Reported Outcome Measures collected at sixmonth follow up show association with severity of stroke on admission to hospital. These outcome measures were shown to be worse in women and those who had suffered a haemorrhagic stroke. This study shows that stroke-specific PROMs, developed by the stroke community itself, are useful for quantifying patient's symptoms and should be advocated. A new, stroke-specific PROM, will help the stroke community better evaluate the long-term outcomes that actually matter to stroke survivors themselves.

Author Contributions: J.H. and B.C. conceived the study. J.H., K.W., S.G., A.P. and B.C. contributed to study development and implementation. J.H., B.C. and N.B. wrote the first draft of the manuscript. All authors contributed to subsequent manuscripts. K.W. completed final draft for publication. All authors have read and agreed to the published version of the manuscript.

Funding: This research was funded by the Stroke Implementation Group of the Welsh Government.

Institutional Review Board Statement: Ethical approval was obtained from the North West-Greater Manchester South Research Ethics Committee on 26 April 2017 (REC number 17/NW/0269, IRAS reference number 222226).

Informed Consent Statement: Participants provided written informed consent via post. Consent via proxy was used to enable a designee to offer consent on behalf of a participant who required physical assistance with completing the questionnaire.

Data Availability Statement: Not applicable.

Conflicts of Interest: The authors declare no conflict of interest. 
Appendix A

\begin{tabular}{|c|c|c|c|c|c|c|}
\hline & $\begin{array}{c}\text { Please respond to each item by marking } \\
\text { one box per row }\end{array}$ & Excellent & $\begin{array}{l}\text { Very } \\
\text { good }\end{array}$ & Good & Fair & Poor \\
\hline $\begin{array}{l}\text { Global } \\
01\end{array}$ & In general, would you say your health is: & $\square$ & $\square$ & $\begin{array}{l}\square \\
\end{array}$ & $\square$ & $\square$ \\
\hline $\begin{array}{l}\text { Global } \\
02\end{array}$ & $\begin{array}{l}\text { In general, would you say your quality of } \\
\text { life is: }\end{array}$ & $\square$ & $\square$ & $\square$ & $\square$ & $\square$ \\
\hline $\begin{array}{l}\text { Global } \\
03\end{array}$ & $\begin{array}{l}\text { In general, how would you rate your physical } \\
\text { health? }\end{array}$ & $\square$ & $\square$ & $\square_{3}$ & 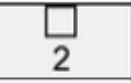 & $\square$ \\
\hline $\begin{array}{l}\text { Global } \\
04\end{array}$ & $\begin{array}{l}\text { In general, how would you rate your mental } \\
\text { health, including your mood and your ability to } \\
\text { think? }\end{array}$ & $\square$ & $\square$ & $\square$ & $\square$ & $\square$ \\
\hline $\begin{array}{l}\text { Global } \\
05\end{array}$ & $\begin{array}{l}\text { In general, how would you rate your satisfaction } \\
\text { with your social activities and relationships? }\end{array}$ & $\square$ & $\square$ & $\square$ & $\square$ & $\square$ \\
\hline \multirow[t]{2}{*}{$\begin{array}{l}\text { Global } \\
09\end{array}$} & $\begin{array}{l}\text { In general, please rate how well you carry out } \\
\text { your usual social activities and roles. (This } \\
\text { includes activities at home, at work and in your } \\
\text { community, and responsibilities as a parent, } \\
\text { child, spouse, employee, friend, etc.) }\end{array}$ & $\square$ & $\square$ & $\square$ & $\square$ & $\square$ \\
\hline & & Completely & Mostly & Moderately & $\begin{array}{c}\text { A } \\
\text { Little }\end{array}$ & $\begin{array}{c}\text { Not At } \\
\text { All }\end{array}$ \\
\hline \multirow[t]{2}{*}{$\begin{array}{l}\text { Global } \\
06\end{array}$} & $\begin{array}{l}\text { To what extent are you able to carry out your } \\
\text { everyday physical activities such as walking, } \\
\text { climbing stairs, carrying groceries, or moving a } \\
\text { chair? }\end{array}$ & $\frac{\square}{5}$ & 4 & 3 & $\square$ & 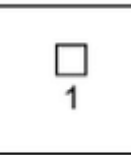 \\
\hline & In the past 7 days & Never & Rarely & Sometimes & Often & Always \\
\hline \multirow[t]{2}{*}{$\begin{array}{l}\text { Global } \\
10\end{array}$} & $\begin{array}{l}\text { How often have you been bothered by } \\
\text { emotional problems such as feeling anxious, } \\
\text { depressed or irritable? }\end{array}$ & $\square$ & $\square$ & $\square$ & $\square$ & $\square$ \\
\hline & & None & Mild & Moderate & Severe & $\begin{array}{c}\text { Very } \\
\text { Severe }\end{array}$ \\
\hline $\begin{array}{l}\text { Global } \\
08\end{array}$ & How would you rate your fatigue on average? & $\square$ & $\square$ & $\square_{3}$ & $\square$ & $\square$ \\
\hline $\begin{array}{l}\text { Global } \\
07\end{array}$ & How would you rate your pain on average? & $\begin{array}{lll} & \square & \square \\
0 & 1 & 2 \\
\text { No } & \\
\text { Pain }\end{array}$ & $\begin{array}{ll}\square & \square \\
3 & 4\end{array}$ & $\begin{array}{ll}\square \\
5\end{array}$ & $\square$ & $\begin{array}{l}\square \\
10 \\
\text { Worst } \\
\text { ginable } \\
\text { Pain }\end{array}$ \\
\hline
\end{tabular}

\section{Scoring:}

Re-code Global07. The recoded score ranges from 1 to 5 .

(0 No pain $=5 ; 1,2$, or $3=4 ; 4,5$, or $6=3 ; 7,8$, or $9=2 ; 10$ worst pain imaginable $=1$ )

After recoding, the

Global Physical Health score $=$ SUM responses to G03 + G06 + G07 + G08 .

Global Mental Health score $=$ SUM G02 + G04 + G05 + Global 10 .

Figure A1. Cont. 


\section{RiksStroke}

Are you able to walk?

$\square \quad$ Able to walk without help from another person with or without a device

$\square \quad$ Able to walk with help from another person

口 Unable to walk

Do you need help to go to the toilet?

$\square \quad$ I can manage without assistance

$\square \quad$ I need help to go to the toilet

Do you need help with dressing/undressing?

I can manage dressing/undressing without help

$\square \quad$ I need help dressing/undressing

\section{International Consortium for Health Outcome Measurement (ICHOMC)}

Do you need a tube for feeding?

$\square \quad$ No

$\square \quad$ Yes

Do you have problems with communication or understanding?

$\square \quad$ No

$\square \quad$ Yes

Figure A1. The 15 questions used in the PROM. 
Table A1. Trial Cohort Demographics for Completers, Non-Completers and Non-Responders.

\begin{tabular}{|c|c|c|c|c|}
\hline & & $\begin{array}{l}\text { Completed } \\
\text { Follow-Up }\end{array}$ & $\begin{array}{l}\text { Did Not Complete } \\
\text { Follow-Up }\end{array}$ & Total \\
\hline \multicolumn{2}{|c|}{ Number of Participants } & $348(16.3 \%)$ & $1726(6.4 \%)$ & 2074 \\
\hline \multirow{5}{*}{ Grouped Age } & $<60$ & $47(13.5 \%)$ & $317(18.4 \%)$ & $364(47.6 \%)$ \\
\hline & $60-69$ & $93(26.7 \%)$ & $302(17.5 \%)$ & $395(16.4 \%)$ \\
\hline & $70-79$ & $122(35.1 \%)$ & $492(28.5 \%)$ & $614(21.1 \%)$ \\
\hline & $80-89$ & $77(22.1 \%)$ & $475(27.5 \%)$ & $552(13.0 \%)$ \\
\hline & $\geq 90$ & $9(2.6 \%)$ & $140(8.1 \%)$ & $149(2.0 \%)$ \\
\hline \multirow[t]{3}{*}{ Sex } & Female & $135(38.8 \%)$ & $797(46.1 \%)$ & $932(44.9 \%)$ \\
\hline & & $135(38.8 \%)$ & $797(46.1 \%)$ & $932(44.9 \%)$ \\
\hline & No symptoms & $23(14.0 \%)$ & $141(86.0 \%)$ & $164(7.9 \%)$ \\
\hline \multirow{5}{*}{$\begin{array}{l}\text { NIHSS Grouped } \\
\text { Frequencies }\end{array}$} & $\begin{array}{l}\text { Mild } \\
\text { Moderate }\end{array}$ & $167(19.2 \%)$ & $701(80.8 \%)$ & $868(41.9 \%)$ \\
\hline & Moderate & $133(17.2 \%)$ & $639(82.8 \%)$ & $772(37.2 \%)$ \\
\hline & $\begin{array}{c}\text { Moderate-Severe } \\
\text { Severe }\end{array}$ & $14(15.2 \%)$ & $78(84.8 \%)$ & $92(4.4 \%)$ \\
\hline & & $4(4.9 \%)$ & $77(95.1 \%)$ & $81(3.9 \%)$ \\
\hline & Mlissing & 7 & 90 & 97 \\
\hline \multirow[t]{3}{*}{ Thrombolysis Status } & Received & $69(20.2 \%)$ & $237(14.2 \%)$ & $306(15.3 \%)$ \\
\hline & 0 & $92(23.7 \%)$ & $296(76.3 \%)$ & $388(24.1)$ \\
\hline & 1 & $81(22.3 \%)$ & $282(77.7 \%)$ & $363(22.6 \%)$ \\
\hline \multirow{4}{*}{$\begin{array}{c}\text { Modified } \\
\text { Rankin Classification }\end{array}$} & 2 & $40(17.0 \%)$ & $195(83.0 \%)$ & $235(14.6 \%)$ \\
\hline & 3 & $43(13.8 \%)$ & $269(86.2 \%)$ & $312(19.4 \%)$ \\
\hline & 4 & $20(9.9 \%)$ & $182(90.1 \%)$ & $202(12.6 \%)$ \\
\hline & 5 & $3(2.8 \%)$ & $106(97.2 \%)$ & $109(6.8 \%)$ \\
\hline \multirow{4}{*}{ Stroke Classification } & Missing & 69 & 396 & 465 \\
\hline & Ischaemic & 308 (16.7\%) & $1533(83.6 \%)$ & $1841(88.8 \%)$ \\
\hline & Haemorrhagic & $35(17.2 \%)$ & $169(82.8 \%)$ & $204(9.8 \%)$ \\
\hline & Not Specified & $5(17.2 \%)$ & $24(82.8 \%)$ & $29(1.4 \%)$ \\
\hline
\end{tabular}

\section{References}

1. EuroQol-A new facility for the measurement of health-related quality of life. Health Policy 1990, 16, 199-208. [CrossRef]

2. Brazier, J.E.; Harper, N.M.; Jones, A.; O'Cathain, K.J.; Thomas, T.; Usherwood, T.; Westlake, L. Validating the SF-36 health questionnaire: A new outcome measure for primary care. Br. Med. J. 1992, 305, 160-164. [CrossRef]

3. Cameron, L.J.; Wales, K.; Casey, A.; Pike, S.; Jolliffe, L.; Schneider, E.J.; Christie, L.J.; Ratcliffe, J.; Lannin, N.A. Self-reported quality of life following stroke: A systematic review of instruments with a focus on their psychometric properties. Qual. Life Res. 2021, 1-14. [CrossRef]

4. Salinas, J.; Sprinkhuizen, S.M.; Ackerson, T.; Bernhardt, J.; Davie, C.; George, M.G.; Gething, S.; Kelly, A.G.; Lindsay, P.; Liu, L.; et al. An International Standard Set of Patient-Centered Outcome Measures After Stroke. Stroke 2016, 47, 180-186. [CrossRef]

5. Kelley, T.A. International Consortium for Health Outcomes Measurement (ICHOM). Trials 2015, 16, 04. [CrossRef]

6. Hewitt, J.; Pennington, A.; Smith, A.; Gething, S.; Price, M.; White, J.; Dewar, R.; Carter, B. A multi-centre, UK-based, noninferiority randomised controlled trial of 4 follow-up assessment methods in stroke survivors. BMC Med. 2019, 17, 111. [CrossRef]

7. Smith, A.; Pennington, A.; Carter, B.; Gething, S.; Price, M.; White, J.; Dewar, R.; Hewitt, J. Acceptability of the method of administration of a patient-reported outcome measure (PROM) with stroke survivors, a randomised controlled trial protocol. Trials 2018, 19, 349. [CrossRef]

8. World Health Organization. The ICD-10 Classification of Mental and Behavioural Disorders: Clinical Descriptions and Diagnostic Guidelines; World Health Organization: Geneva, Switzerland, 1992.

9. Kwah, L.K.; Diong, J. National Institutes of Health Stroke Scale (NIHSS). J. Physiother. 2014, 60, 61. [CrossRef]

10. Odderson, I.R. The National Institutes of Health Stroke Scale and Its Importance in Acute Stroke Management. Phys. Med. Rehabil. Clin. N. Am. 1999, 10, 787-800. [CrossRef]

11. Saver, J.L.; Filip, B.; Hamilton, S.; Yanes, A.; Craig, S.; Cho, M.; Conwit, R.; Starkman, S.; for the FAST-MAG Investigators and Coordinators. Improving the reliability of stroke disability grading in clinical trials and clinical practice: The Rankin Focused Assessment (RFA). Stroke 2010, 41, 992-995. [CrossRef]

12. Alonso, J.; Bartlett, S.J.; Rose, M.; Aaronson, N.K.; Chaplin, J.E.; Efficace, F.; Leplège, A.; Lu, A.; Tulsky, D.S.; Raat, H.; et al. The case for an international patient-reported outcomes measurement information system (PROMIS ${ }^{\circledR}$ ) initiative. Health Qual. Life Outcomes 2013, 11, 210. [CrossRef]

13. Hays, R.D.; Schalet, B.D.; Spritzer, K.L.; Cella, D. Two-item PROMIS ${ }^{\circledR}$ global physical and mental health scales. J. Patient Rep . Outcomes 2017, 1, 2. [CrossRef] [PubMed] 
14. Asplund, K.; Hulter Åsberg, K.; Appelros, P.; Bjarne, D.; Eriksson, M.; Johansson, A.; Jonsson, F.; Norrving, B.; Stegmayr, B.; Terént, A.; et al. The Riks-Stroke story: Building a sustainable national register for quality assessment of stroke care. Int. J. Stroke 2011, 6, 99-108. [CrossRef]

15. Palmcrantz, S.; Sommerfeld, D.K. Development and validation of the Swedish national stroke register Riksstroke's questionnaires in patients at 3 and 12 months after stroke: A qualitative study. BMJ Open 2018, 8, e018702. [CrossRef]

16. Hays, R.D.; Bjorner, J.B.; Revicki, D.A.; Spritzer, K.L.; Cella, D. Development of physical and mental health summary scores from the patient-reported outcomes measurement information system (PROMIS) global items. Qual. Life Res. Int. J. Qual. Life Asp. Treat. Care Rehabil. 2009, 18, 873-880. [CrossRef]

17. Duncan, P.W.; Wallace, D.; Lai, S.M.; Johnson, D.; Embretson, S.; Laster, L.J. The stroke impact scale version 2.0. Evaluation of reliability, validity, and sensitivity to change. Stroke 1999, 30, 2131-2140. [CrossRef]

18. Van Straten, A.; De Haan, R.J.; Limburg, M.; Schuling, J.; Bossuyt, P.M.; Van den Bos, G.A. A stroke-adapted 30-item version of the Sickness Impact Profile to assess quality of life (SA-SIP30). Stroke 1997, 28, 2155-2161. [CrossRef]

19. Soto-Cámara, R.; González-Santos, J.; González-Berna, J.; Trejo-Gabriel-Galán, J.M. Factors associated with a rapid call for assistance for patients with ischemic stroke. Emerg. Rev. Soc. Esp. Med. Emerg. 2020, 32, 33-39.

20. Rossnagel, K.; Jungehülsing, G.J.; Nolte, C.H.; Müller-Nordhorn, J.; Roll, S.; Wegscheider, K.; Villringer, A.; Willich, S.N. Out-of-hospital delays in patients with acute stroke. Ann. Emerg. Med. 2004, 44, 476-483. [CrossRef]

21. Gall, S.; Phan, H.; Madsen, T.E.; Reeves, M.; Rist, P.; Jimenez, M.; Lichtman, J.; Dong, L.; Lisabeth, L.D. Focused Update of Sex Differences in Patient Reported Outcome Measures After Stroke. Stroke 2018, 49, 531-535. [CrossRef]

22. Farace, E.; Alves, W. Do women fare worse: A metaanalysis of gender differences in traumatic brain injury outcome. Neurosurg. Focus 2000, 8, e6. [CrossRef]

23. Holbrook, T.L.; Hoyt, D.B. The impact of major trauma: Quality-of-life outcomes are worse in women than in men, independent of mechanism and injury severity. J. Trauma 2004, 56, 284-290. [CrossRef] [PubMed]

24. Norris, C.M.; Ghali, W.A.; Galbraith, P.D.; Graham, M.M.; Jensen, L.A.; Knudtson, M.L.; the APPROACH Investigators. Women with coronary artery disease report worse health-related quality of life outcomes compared to men. Health Qual. Life Outcomes 2004, 2, 21. [CrossRef]

25. Roquer, J.; Campello Ana, R.; Gomis, M. Sex Differences in First-Ever Acute Stroke. Stroke 2003, 34, 1581-1585. [CrossRef]

26. Kapral Moira, K.; Fang, J.; Hill Michael, D.; Silver, F.; Richards, J.; Jaigobin, C.; Cheung Angela, M. Sex Differences in Stroke Care and Outcomes. Stroke 2005, 36, 809-814. [CrossRef] [PubMed]

27. Andersen Klaus, K.; Olsen Tom, S.; Dehlendorff, C.; Kammersgaard Lars, P. Hemorrhagic and Ischemic Strokes Compared. Stroke 2009, 40, 2068-2072. [CrossRef]

28. Jørgensen, H.S.; Nakayama, H.; Raaschou, H.O.; Olsen, T.S. Intracerebral hemorrhage versus infarction: Stroke severity, risk factors, and prognosis. Ann. Neurol. 1995, 38, 45-50. [CrossRef] [PubMed]

29. Saposnik, G.; Cote, R.; Phillips, S.; Gubitz, G.; Bayer, N.; Minuk, J.; Black, S. Stroke Outcome in Those Over 80. Stroke 2008, 39 , 2310-2317. [CrossRef] [PubMed]

30. Katzan, I.L.; Thompson, N.R.; Lapin, B.; Uchino, K. Added Value of Patient-Reported Outcome Measures in Stroke Clinical Practice. J. Am. Heart Assoc. 2017, 6, e005356. [CrossRef] 